\title{
HUMANISTAS DE CASTILLA Y LEÓN ANTE LA REALIDAD DE LA AMÉRICA HISPÁNICA
}

\author{
Mariano CUESTA DOMINGO
}

Recibido: $18 / 05 / 2012$

Aceptado: 19/10/2012

\begin{abstract}
RESUMEN: Tres segovianos singulares presentan su visión de la América hispánica. Sus diferentes épocas, formaciones, dedicaciones, personalidades, religiosidad y sesgo influyen en su trabajo y enriquecen el conocimiento sobre la materia.
\end{abstract}

PALABRAS CLAVE: Domingo de Soto, Antonio de Herrera, Diego de Avendaño, historiografía americana.

ABSTRACT: Three singular persons from Castilla and Leon present their vision about Hispanic America. Their different time, background, activity, personality, piety and bias influence their work and enrich the knowledge about the subject.

KEYWORDS: Domingo de Soto, Antonio de Herrera, Diego de Avendaño, american historiography.

\section{INTRODUCCIÓN}

Aparentemente poco tienen en común los tres personajes si se exceptúa lo prolífico de su pluma, su longevidad, el paisanaje y la materia prioritaria de su actividad: Soto y Avendaño eran naturales de la ciudad de Segovia, Herrera de la villa de Cuéllar. Soto es un pensador, Herrera un historiador, Avendaño un profesor y viajero. Lo demás los diferencia por completo: la época en que vivieron, la actividad más destacada en la que brillaron, su formación y dedicación, su personalidad, su adscripción religiosa dentro de una confesionalidad cristiana (dominico, seglar y jesuita, respectivamente), su actitud ante la materia americana, su aportación a la Historia de la Cultura. Y es ahí donde vuelven a confluir sus trayectorias bio-bibliográficas, a la mayor gloria de las letras americanas, españolas, y, en particular, de las castellano-leonesas.

No fueron o son los únicos segovianos cuya participación en la Historia de América sea notoria, otros más brillaron en diferentes acciones y actividades 
diversas; su aportación fue estudiada hace unos años en un Congreso celebrado en el mismo centro universitario que lleva el nombre de Soto y cuyas actas fueron publicadas en su momento ${ }^{1}$. Entonces se vio hasta qué punto y con cuánta intensidad gentes de aquel territorio se hallaron presentes desde el primer viaje colombino hasta la actualidad, en todas las actividades tanto descubridoras y exploradoras como colonizadoras; en aspectos historiográficos, migratorios, evangelizadores con una repercusión toponímica que tuvo su mayor énfasis en América y el Filipinas; un protagonismo llevado a cabo por eclesiásticos, por hombres de gobierno y de armas. En el siglo XVI y también en los sucesivos; unos personajes tan notorios $\mathrm{y}$, algunos tan controvertidos como, entre tantos otros, Diego Velázquez de Cuellar, Pedrarias Dávila, Andrés Laguna y hasta unas Ordenanzas importantes para las Indias fueron firmadas en el Bosque de Segovia ${ }^{2}$. Para la presente ocasión, son objeto de atención tres intelectuales mencionados: Soto, Herrera y Avendaño.

\section{TRES BIOGRAFÍAS DISPARES}

Acaba de ser subrayado el paisanaje como uno de los elementos comunes, son castellanos, son segovianos de nacimiento; ninguna de los tres personajes regresó a Segovia para impulsar su progreso, su cultura; incluso Soto, que pudo ser obispo de la diócesis, renunció a tal honor por seguir su vocación docente.

\subsection{Domingo de Soto}

Soto nació en la ciudad de Segovia (1494 o 1495) en una familia modesta y llegó a ser una de las grandes figuras españolas del siglo XVI; su nombre de pila fue Francisco que más adelante cambiaría por el que es más conocido. Joven, aprendió gramática latina con maestros preceptores, humanistas. Pasó a Alcalá de Henares (1510) y fue discípulo de Tomas de Villanueva (que llegó a ser santo) con quien aprendió letras y virtud; graduado bachiller (1516) conoció a sendos catedráticos segovianos de la Universidad de París, Luis y Antonio Coronel, cuyo apoyo le permitió estudiar en la capital francesa (1517-1519); allí conoció a Francisco de Vitoria.

En 1520 ya se hallaba en la Universidad de Alcalá donde el maestro Francisco de Soto explicó Filosofía mostrándose como un excepcional intérprete de Aristóteles y explicando las Summulas; entre sus discípulos se halla el beato Juan de Ávila.

\footnotetext{
${ }^{1}$ Cuesta Domingo, M. (edic. y dir., 1992). Proyección y presencia de Segovia en América. Segovia: Colegio Universitario "Domingo de Soto".

2 Cuesta Domingo, M. (1994). Normativa para descubrimientos y Ordenanzas del Bosque de Segovia. Segovia: Colegio Universitario "Domingo de Soto".
} 
En Burgos, tomó el hábito de Santo Domingo (julio de 1524); es cuando cambió su nombre por el del fundador de la Orden. Poco después se hallaba en la Universidad de Salamanca, en el Convento de San Esteban y obtuvo la cátedra de Vísperas, de Teología (1532). Juntamente con Vitoria y otros más elevaron la categoría de Salamanca hasta sus mayores cotas; fue entonces cuando el ya Domingo de Soto se vio incitado a publicar sus cursos, las Summulas, la Lógica y la Física, revitalizando la obra de Aristóteles.

En sus relecciones, sobre los problemas filosófico-políticos de la época, se percibe un claro antecedente de las también famosas lecciones magistrales de Francisco de Vitoria y poco después, un acontecimiento contribuyó a incrementar su fama en la Corte: el príncipe Felipe contraía matrimonio con María de Portugal en Salamanca (1543) y, en aquellos días tuvo oportunidad de escuchar una lección de Soto; su oratoria le impresionó y su prestigio fue grande ante Carlos V y el futuro Felipe II; pasó a ser confesor del Emperador.

Figura 1. Emblema y leyenda de Domingo de Soto (en sus ediciones)

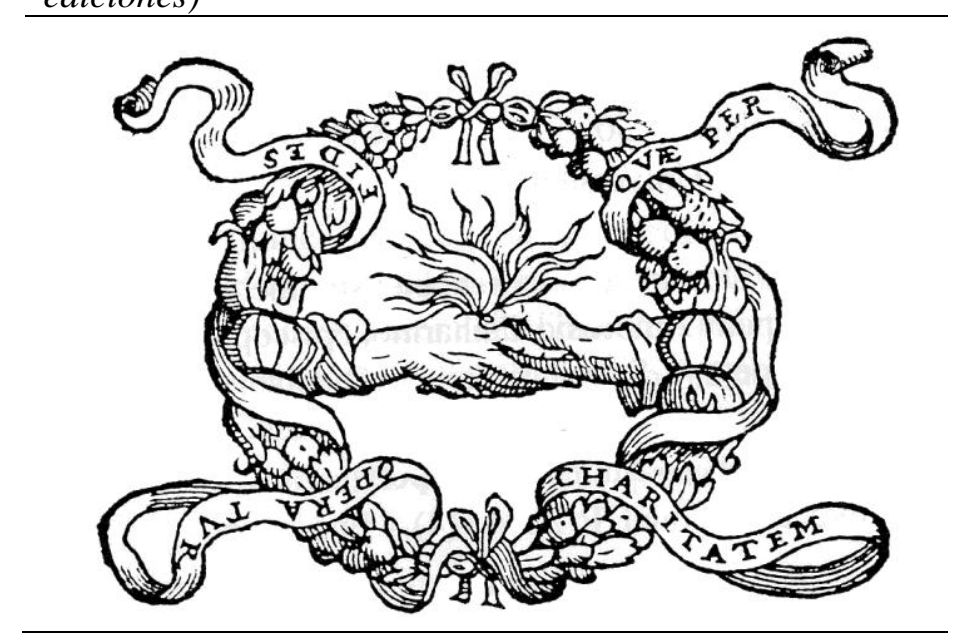

Su importante participación en el Concilio de Trento también está acreditada, fue benemérita; contribuyó a darle a conocer entre sus contemporáneos, su fama de sabio se vio reforzada mediante con la publicación de sus obras teológicas, que se imprimieron muchas veces y no solo en España, sino también en Venecia, Lyon, 
París, Amberes, etc. ${ }^{3}$. Fue premiado con un emblema consistente en dos manos que se estrechan de cuyo lazo salen unas llamas y una leyenda que son palabras de San Pablo a los Gálatas: "Fides quae per charitatem operatur", que puede verse en algunas de las impresiones de sus obras.

Soto no quería permanecer alejado de las aulas y en cuanto tuvo ocasión se reincorporó a la docencia a costa de rechazar el obispado de Segovia, según su propia expresión, porque no soy para tan gran empleo, y subraya: a mi me llamó Dios a la religión y me destinó sin duda a las escuelas y cartapacios por ello pidió se le trocara ese favor en darme licencia para volver á mis estudios. En 1550 se hallaba de nuevo en Salamanca, renunciado también el cargo de confesor del Emperador.

No se le han escatimado los elogios a sus muchos méritos por parte de sus contemporáneos, como el padre Granada y fray Luis de León y de otros escritores que de él trataron. Fray Luis de León, por ejemplo, le dedicó una oración fúnebre repleta en alabanzas:

Te justissimum, te religiossimum, te temperatissimum, incredibili gravitate, integritate, prudentia, fortitudine praeditum, nulli unquam aut vitio succubuisse, aut voluntati hominis minus juste cessisse; omnia a te ex aequo et bono, nihil gratiae causa aut dixisse, aut senssise; veritatis dicendae atque tuendae, quam regum favorem mendatiis, ut fit nunc, et assentatione promerendi, studum tibi antiquius fuisse. Cumque nullius hominis cupiditati servitute servires, obstares saepe potius et adversares, quamplurimis tamen et a rege et a regni proceribus omnes prope semper majores causas ad tuum judicium, arbitrium, concilium delatas fuisse; tuae illos virtuti magna praemia obtulisse; a te majori virtute spreta illa semper et repudiata fuisse. Haec, inquam, atque illa de te, Soto, posteri omnes memoria repetent ${ }^{4}$.

Finalmente, en su aspecto personal, Domingo de Soto era un hombre un tanto severo y riguroso en lo que consideraba justo; de temperamento reflexivo, tranquilo, retraído y ajeno a ambiciones, sobresalió como filósofo, teólogo, fue un admirado catedrático de universidad y un querido profesor. Se sintió siempre un teólogo; desde esa condición trató los temas acerca del derecho, de la política, de la filosofía, de la economía, etc. Frecuentemente era citado por sus discípulos y seguidores apoyándose en él como autoridad de prestigio.

\footnotetext{
3 Cuesta Domingo, M. del P. (1996). Domingo de Soto y su obra. Segovia: Colegio Universitario.

${ }^{4}$ Beltrán De Heredia, V. (1961). Domingo de Soto: estudio biográfico documentado. Cultura Hispánica: Madrid, p. 600.
} 


\subsection{Antonio de Herrera}

El segundo intelectual de referencia es Antonio de Herrera y Tordesillas; con él surge la figura del historiador. Cuando publicó sus Décadas, la obra podía ser considerada como la primera Historia contemporánea de América; pero, además, escribió Historia universal, crónica y otra literatura de variada índole.

Figura 2. Efigie de Herrera en el Medallón procedente de la portada de las Décadas con la indicación del nacimiento del autor

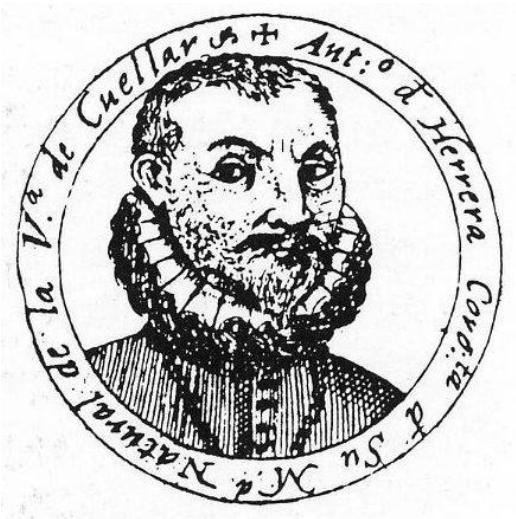

De él son suficientemente conocidos el inicio de su orto (1549, en Cuéllar) ${ }^{5}$ $\mathrm{y}$ el final de su ocaso (1625, en Madrid); se sabe que era hijo de Rodrigo de Tordesillas e Inés de Herrera, que pasó la infancia en su villa natal, que estaba dotado de inteligencia y capacidad de trabajo y que aprendió latín, idioma que perfeccionó cuando aprendió italiano, en Roma. Están documentados sus matrimonios, que le facilitaron su situación económica, y tuvo oportunidades de situarse en la Corte y sacar buen provecho de su posición ${ }^{6}$. Fueron setenta y seis años de un trabajador incansable $y$ autor prolífico que aprovechó su producción literaria para ofrecer y dedicar sus obras a personajes principales en aras a la consecución de sus simpatías y apoyo.

${ }^{5}$ Así se aprecia en la portada que abre la Descripción de las Indias, la que precede al tomo primero de sus Décadas: se muestra un medallón con un grabado-retrato de Antonio de Herrera con un letrero a su alrededor que reza: "Antonio de Herrera. Coronista de Su Magestad, de la villa de Cuéllar". Existen otros testimonios que lo ratifican: el sargento mayor Alonso Vázquez, los testamentos y algunas de sus cláusulas, la tradición historiográfica, su enterramiento y lápida mortuoria, etc. Cuesta Domingo, M. (1998). Antonio de Herrera y su obra. Segovia: Colegio Universitario. Cuesta Domingo, M., Rojas, J. L. de y JimÉnez Garcés, J.A. (2009). Antonio de Herrera y Tordesillas, historiador acreditado. Cuéllar (Segovia): Ayuntamiento.

${ }^{6} 1570$ En Italia, entró al servicio de Vespasiano Gonzaga.-1575 En Navarra, con Gonzaga.-1579 En Valencia, con Gonzaga, pero fijó su residencia en la Corte.-1581 Se casó con Juana de Esparza y Artieda.- 1583 Fue administrador de una propiedad del marqués de Espejo.- 1584 Falleció su esposa.1586 Murió Vespasiano Gonzaga.- 1587 Falleció su hija Juana.- 1596 Fue nombrado Cronista Mayor de Indias.- 1596 Contrajo matrimonio con María de Torres.- 1606 Fijó su residencia en Madrid, con la Corte.- 1609-1611, Herrera sufrió arresto domiciliario.- 1622 Herrera firmó su segundo testamento. (Cuesta Domingo, M. (2007). «Los cronistas oficiales de indias. De López de Velasco a Céspedes del Castillo». Revista Complutense de Historia de América, 33, pp. 115-150. 
$\mathrm{Su}$ obra muestra un concepto plausible acerca de la Historia; tuvo verdadero anhelo por localizar y recopilar abundancia de fuentes, por ser exhaustivo; el amplio uso de documentación de archivo que pudo realizar constituye una excelente referencia para permitir afirmar que la obra de Herrera se tiene en pie. No se trata de camuflar los defectos que le han sido achacados al cronista/historiador; el mismo Herrera tuvo ocasión de intuir o percibir, según los casos, parte de la mala crítica y tuvo oportunidad de enunciar una defensa en la misma proporción, comentando cómo los envidiosos acostumbraban a ignorar públicamente lo que luego leen en privado, denostando en otros los que ellos son incapaces de escribir, prefiriendo informarse en obras de mala calidad mejor que en autores bien informados. En expresión de Herrera, muchos que pretender ser doctos sin estudio, no conocen que nada se puede saber sin maestro ni doctrina.

Es una actitud de Herrera que muestra el elevado concepto del oficio de historiador y evidencia su posición epistemológica; sus juicios le condujeron a cierta actitud desconsiderada hacia otros autores respetados posteriormente, como Sahagún, Mendieta y Olmos; es una actitud que le llevó al enfrentamiento tácito (Década V, Libro II, capítulo 4) o manifiesto ${ }^{7}$ con Juan de Torquemada, a quien cita en otro momento, como el que ha escrito una "monarquía indiana" ${ }^{8}$ apostillándole con algunas expresiones delicadas rayanas con la enemistad personal.

Esa disposición combativa de Herrera fue particularmente notoria con otro personaje de la Corte, el Conde de Puñonrostro, por causa del trato propinado por Herrera a Pedrarias Dávila en las Décadas ${ }^{9}$; el proceso es ciertamente interesante para apreciar la seriedad con que Herrera desempeñaba su oficio y mantuvo su criterio con tenacidad incluso ante poderosas gentes de la Corte por encima de eventuales actitudes serviles, lo que demuestra que no siempre supeditó su actitud al poder. El hecho de que el Conde tuviera gran ascendiente en la Corte y de que el Consejo aprobara la publicación de las Décadas dota al proceso de un interés suplementario; Herrera hubo de efectuar alegaciones ${ }^{10}$ y réplicas ${ }^{11}$ y lo efectuó

\footnotetext{
${ }^{7}$ Década VI, libro III, capítulo 19 (Herrera afirma que Torquemada ignoraba los textos de Las Casas, Cervantes de Salazar y Acosta).

${ }^{8}$ En cuya obra Torquemada cita a Antonio de Herrera, como también lo hizo Solórzano Pereira.

${ }^{9}$ Recuérdese que Pedrarias era el abuelo de Francisco Arias Dávila y Bobadilla, el mencionado Conde. Codoin, XXVII.

${ }^{10}$ Verdaderamente interesante la "información y razones por las que ha escrito y cómo lo ha hecho sobre Pedrarias Dávila".- Archivo General de Indias [AGI], Patronato, 18.

${ }^{11}$ En AGI, Patronato, 18 se hallan los documentos por lo que el Conde pidió el envío de una amplia documentación desde Simancas; así como hizo Herrera (aprobado por Real Decreto que quedó
} 
basándose en su criterio acorde con la expresión de ni ocultar verdad ni decir falsedad que debe primar en el historiador. Posición que sustentó con tanta energía y pruebas que la obra salió a la luz pública, como sabemos, sin que Herrera se viera obligado a modificar los textos de sus Décadas, tanto por informes favorables al cronista $^{12}$ como por declaraciones y respuestas al litigante ${ }^{13}$. El pleito se prolongó con el resultado conocido de su inclusión en la Historia general de los hechos sin modificación alguna ${ }^{14}$.

Criterio de historiador que tiene su expresión en algunos de sus Discursos ${ }^{15}$ : Sobre los provechos de la Historia, Del oficio del historiador, Sobre historiadores de la antigüedad y el mérito de las historias e historiadores. También valora Herrera el trabajo del historiador en la dedicatoria de la Historia General del Mundo a Juan de Zúñiga: de donde verá cuán necesarias para que los hombres puedan tomar luz como si anduviesen en guerra, como vuestra excelencia prudentísimamente lo ha dicho a la imitación del gran Alejandro, honrando a los historiadores como en el Mundo necesarios ${ }^{16}$. Una excelente consideración de la Historia que también ratificó Antonio de Herrera y Tordesillas en otra de sus obras: No puede haber cosa para el buen gobierno de la vida humana de más provecho que la noticia de las historias y ninguna más perjudicial que no ser puntualmente escritas $^{17}$.

Y es que Antonio de Herrera y Tordesillas construyó una obra que al decir de Ballesteros Beretta (Proemio, LXXXIV):

No bastaría el hecho de ser la primera historia general de América para ensalzarla si no adornasen a esta obra otros méritos. Herrera es un historiador constructivo, que elabora con talento sus materiales, los distribuya con arte, $y$ del cúmulo inmenso de sucesos destaca los transcendentales y los útiles al relato. Su estilo es claro sin grandes primores

ratificado en su "instancia al Rey solicitando la comprobación de su escrito sobre Pedrarias con la documentación que cita").

12 «Del Colegio Hispano-Booniense en favor de Herrera sobre la cuestión del Conde de Puñonrostro». AGI, Patronato, 18.

${ }^{13}$ AGI, Patronato, 18.

${ }^{14}$ Pues, como decía Herrera, "si con todo eso el Consejo otra cosa hiciere, el Cronista quedará descargado con Dios, que es lo que le importa", AGI, Patronato, 18.

${ }^{15}$ Discursos morales, políticos e históricos inéditos, I-IV.

${ }^{16}$ Herrera y Tordesillas, A. (1601). Historia General del Mundo. Madrid: Luis Sánchez, dedicatoria, parte primera.

${ }^{17}$ Herrera y Tordesillas, A. (1591). Cinco Libros De Antonio De Herrera De La Historia de Portugal, y conquista de las Islas de los Açores, en los años de. 1582. y 1583. Madrid: Pedro Madrugal. 
de dicción y sin fárrago de vocablos innecesarios. Podrá equivocarse, pero sus fuentes son en general dignas de fe. Es el primero que consulta documentos y los pone a contribución rectificando las fuentes historiográficas. Por él se conocieron, siglos antes de imprimirse, los libros de Las Casas y Cervantes de Salazar. Muchos de los escritos utilizados por el cronista probablemente han desaparecidos o se ignora su paradero. Recordado lo anterior, no puede dudarse del valor inestimable de las Décadas de Herrera como tampoco de la Historia General del Mundo y, en general, de toda su obra histórica.

Así pues, la perspectiva histórica a través de Herrera presenta una coherencia que se contrasta con alguna incoherencia en la utopía y realidad indiana; no constituye una excepción en la temática histórica americana; ni siquiera lo fue en la realidad que iba aconteciendo sobre el espacio americano-indiano desde el instante de su descubrimiento oficial. Una legislación prolija, bienintencionada y cambiante a lo largo del siglo XVI y posteriores no es si no el reflejo en la metrópoli de aquellas realidades que sinnúmero de protagonistas se empecinaron en hacer conocer y procuraron perfeccionar. Eran gentes espoleadas por cuanto sucedía ante su presencia; convulsionados por actuaciones que se les antojaba revulsivos pero que, en la Corte, quedaban amortiguadas por la distancia en el espacio y el tiempo y adormecidas por las diferencias y una percepción parcial, incompleta.

Esa paleta de tonalidades estaba producida por la textura cultural y por los intereses del cristal con que cada observador percibe su particular realidad entre la innumerable riqueza de las existentes en América; así como por su transmisión a la Corte que se veía afectada por un efecto multiplicador, paradójicamente, originado por la respuesta, presumiblemente universalizadora, que la Corona o sus órganos de gobierno daban. He ahí la base para eventuales coherencias y claras incoherencias que se traslucirán, inevitablemente, en la historiografía. Herrera, sin compromiso de su parte, recoge evidencias y, en su exposición histórica, da muestra de una gran valentía dialéctica que supo conjugar con una notable prudencia práctica ante una problemática sin solución, en su momento ${ }^{18}$.

\subsection{Diego de Avendaño}

Los Avendaño no escasean en América por lo que tratar de establecer una filogenie que les aúna no es fácil; puede ser interesante pero exige un esfuerzo digno de mejor causa, no obstante Muñoz hace una compilación que resulta

18 Cuesta Domingo, M. (1992). «Coherencia e incoherencia en la utopía y realidad indiana. Perspectiva histórica a través de Herrera». En PereñA, L. y OTROs. Utopía y realidad indiana. Salamanca: Universidad Pontificia, p. 223-238. 
suficiente $^{19}$. Lo importante es que Diego [Didaci, reza en latín, con toda lógica, en las portadas de sus obras] de Avendaño López nació en Segovia el día 29 de septiembre de 1594, en el seno del matrimonio formado poro Diego de Avendaño y Ana López. Joven, marchó a Sevilla y estudió filosofía; allí conoció y trabó amistad con Juan de Solórzano Pereira; con este ilustre jurista marchó hacia Perú cuando Solórzano fue nombrado Oidor de la Audiencia de Lima $(1610)^{20}$; ya en 1626 recomendaba a la corte la publicación del Indiarum Iure del maestro. En aquel entorno geográfico permaneció el segoviano durante medio siglo, "casi cincuenta años", como subraya en los datos autobiográficos anotados en su Thesaurus; Avendaño se lo ratifica el lector cuando relata que el terremoto de Concepción (Chile) ocurrió "en este mismo año" de 1657.

En 1612 había ingresado en la Compañía de Jesús y desde entonces desarrolló lo que ahora se denominaría una amplia actividad docente e investigadora. Fue profesor de Filosofía y Teología en el Colegio Máximo "San Pablo" de Lima, de Teología Prima en Chuquisaca y en la Universidad de San Marcos; fue Rector de la Compañía en Curco, Charcas, Chuquisaca y San Pablo de Lima, así como Provincial jesuítico del Perú. Falleció en 1688 (30 de agosto) en el Colegio de Lima, cuando iba a cumplir los 94 años de edad.

Hombre de "salud integral y armonía de cualidades con un natural sanguíneo bilioso" que parece ratificarse por su increpación a los Virreyes urgiéndoles a aplicar la justicia vindicativa:

Hierva en vosotros el celo por vengar las injurias divinas y por engalanar al pueblo de Dios como grato y partidario de las buenas obras. Limpiad, limpiad, borrad a los autores de inmundicia, a los artífices de impureza e instigadores de pasiones, a las facciones de errores y ladrones; $y$ aún cuando no hagan nada, desterrad, exterminad, aniquilar con el Rey profeta a los perpetradores de todos los males ${ }^{21}$.

Era considerado persona muy espiritual, recogida y muy grande estudiante, dice un compañero jesuita, pero no carente de humor e ironías cáusticas y por más que

19 MuÑOZ García, A. (2001). «Introducción» y traducción de Thesaurus indicus de D. de Avendaño. Pamplona: EunSA. I, 13.

${ }^{20}$ Reacuérdese que en 1629 sería nombrado Consejero de Indias y comenzó a publicar su Indiarum iure y en 1647 su Política indiana.

${ }^{21}$ Avendaño LóPEZ, D. de (2001-2003). Thesausrus Indicus [1668]. Ed. de A. Muñoz García. Pamplona: Universidad de Navarra: 2 vols. Tit. III, número 80; ver también MuÑOZ GARCíA, A. (2003). Diego de Avendaño (1594-1698): filosofía, moralidad, derecho y política en el Perú colonial. Lima: Universidad Nacional Mayor de San Marcos. 
viviera en Perú mantuvo una actitud de permanente recuerdo a su tierra natal y la mejor opinión sobre sus reyes; esta nota subrayada por Muñoz García (pág. 18 y ss.) se complementa con otras características como las de su carácter de moralista, su formación jurista y su actividad escritora.

\section{TRES APORTACIONES DESTACABLES}

En cuanto a las aportaciones literarias de los tres segovianos, debe subrayarse, ya se ha enunciado, su producción abundante en títulos y número de páginas; sus contenidos acordes con la formación, dedicación e intencionalidad de cada autor, también su dominio del latín. El resultado, al alcance de todos, a la altura de los niveles logrados por cada uno de ellos.

\subsection{Domingo de Soto}

La expresión valorativa de su obra que se utiliza casi como su propio lema, Qui scit Sotum scit totum ${ }^{22}$, le confiere a este segoviano de una categoría extraordinaria en su tiempo, quizá interpretada literalmente puede parecer hiperbólico, por encima de sus merecimientos, pero no deja de tener su aspecto ilustrativo acerca de Domingo de Soto y sus escritos. La obra del propio dominico fue editada por impresores cuyo símbolo, el ave fénix y su capacidad de auto regeneración, era concordante con la figura del dominico y recuerda la simbología del pelícano en algún rey Portugués casi coetáneo.

Publicaba continuamente sus manuscritos, fuera sobre la pobreza o sobre la dialéctica, la lógica, el Comentario a la Isagoge o libro de los Predicables de Porfirio, el comentario al de los Predicamentos o las Categorías y a los de los Posteriores o "De Demonstratione" de Aristóteles, el Comentario a los Físicos y las Cuestiones sobre los mismos, etc., obras estas últimas, en las que se ponían de manifiesto los profundos conocimientos que Soto adquirió sobre estas materias durante sus estudios en Alcalá y en París; un ejemplo de su deseo de estar al día en los conocimientos científicos y sus avances lo demuestra el hecho de que Domingo de Soto tiene el mérito de haber formulado las leyes de la caída de los cuerpos, sesenta años antes que Galileo, con motivo de una breve estancia de Soto en París, según pone de manifiesto Sebastián Dormido ${ }^{23}$, Pierre Duhem y y William Wallace.

22 Cuesta Domingo, M.P. (2008). «La obra de Soto; qui scit Sotum, scit totum». En Cuesta Domingo, M. (Coord. y ed.). Domingo de Soto en su Mundo. Segovia: Colegio Universitario Domingo de Soto.

${ }^{23}$ Dormido Bencomo, S. (2007). «Cuestiones de Física y el tema de la gravedad en Domingo de Soto». En Domingo de Soto en su mundo. DuHEM, P.M.M. (1913). Les précurseurs parisiens de Galilée. 
Figura 3. Marcas de impresión de obras de Soto con sendos lemas que hubieran encajado bien en el dominico

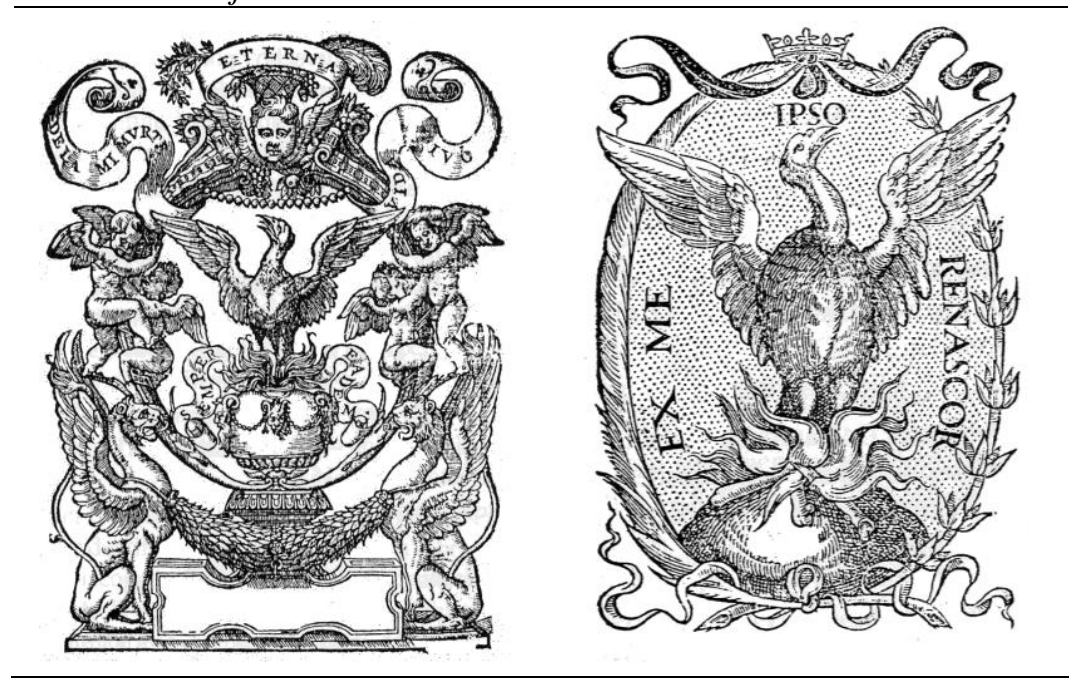

Sobre la indigencia, Domingo de Soto escribió, en latín y español, un tratado en defensa de los pobres, titulado "Deliberación en la causa de los pobres" (Salamanca, 1545); en él exponía cuánto interesaba conservar y aumentar la caridad a la vez que reflexionaba sobre la conveniencia de no consentir la existencia de vagabundos por ser origen de tantos daños. Resultó ser uno de los textos más razonados, humanitarios y profundos del derecho cuando se trata del pauperismo. Su pensamiento dejó una huella profunda ${ }^{24}$. La referida obra fue recibida muy bien, como también lo habían sido la segunda edición corregida y aumentada de las Summulas (1539). Esta obra, como las anteriores, tuvieron un gran éxito; incluso sirvieron como texto en varias universidades españolas y en México.

La magnitud territorial de España y el equivalente de sus problemas y responsabilidades en el Viejo y en el Nuevo Mundo dieron lugar a controversias, de diversa índole que influyeron sobre la colonización de América y que tuvieron su caja de resonancia también en el Concilio de Trento. En toda la problemática se

Paris, Hermann. Wallace, W. A. (1976). «El enigma de Domingo de Soto: "Un informiter difformis" y la caída de los cuerpos en la tardía física medieval». Studium, 16, pp. 343-367.

${ }^{24}$ Velarde Fuertes, J. (1992). «El inicio de la economía moderna en España con especial condenación de Domingo de Soto», en Cuesta Domingo (edit. y dir) [nota 2] Segovia, pp. 359-396. 
vio inmerso el teólogo segoviano. Su obra, veinte obras publicadas de las cuales, quince títulos son de materia teológica y cinco lo son de índole jurídica, se reseñan a continuación ${ }^{25}$ :

1. Annotationes in commentarios Ioannis Feri Moguntinensis super Euangelium Ioannis. excudebat Andreas à Portonariis. Salmanticae, 1554.

2. Apologia qua Catharino de certitudine gratia respondet. Apud Nicolaum de Bascharinis. Venteéis, 1547.

3. Concio extremo Indicio. S.1. : s.n., 1545.

4. De cauendo iuramentorum abusu ad laudem diuini nominis institutio. Excudebat Andreas de Portonariis. Salmanticae, 1551.

5. De iustitia et iure libri decem. excudebat Andreas à Portonariis. Salmanticae, 1553 (1554).

6. De Natura \& Gratia. Apud Iuntas: expensis haeredum Lucae Antonij Iuntae. Venetiis, 1547.

7. In causa pauperum deliberatio. en la officina de Iua[n] de Iu[n]ta. Salamanca, 1545.

8. In Dialecticam Aristotelis commentarii. J. de Junta. Salamanca, 1543.

9. In epistolam ad Romanos commentarii. In aedib. Ioan. Steelsii. Antuerpiae, 1550.

10.In Porphirii isagogen ... commentarii. B. Junta y hermanos. Venecia, 1574.

11.In Quartum Sententiarum commentarii. Excudebat Ioannes à Canoua. Salmanticae, 1557 (1558).

12.Relección "De dominio", edición por Jaime Brufau Prats. Universidad. Granada, 1964.

${ }^{25}$ De forma exhaustiva en Cuesta, M. del P. Domingo de Soto y su obra [nota 23]. Respecto a la obra manuscrita de Soto, se trata de lecciones universitarias, autógrafos o copiados conservados en la Universidad Complutense, Archivo Histórico Nacional, Archivo Histórico Nacional, Biblioteca Nacional de España, Biblioteca de El Escorial, Universidad de Granada, Cabildo de Palencia, Universidad de Salamanca, Convento de San Esteban de Salamanca, Universidad de Sevilla, Biblioteca del Patriarca de Valencia, Universidad de Munich, Archivo de la Compañía de Jesús de Roma, Archivo General de la Orden de Predicadores de Roma, Biblioteca Vaticana, Biblioteca Nacional de México y Biblioteca Pública de Évora. 
13.Relección "De legibus". Cátedra "Francisco Suarez". Granada, 1965.

14.Relectio de ratione tegendi et detegendi secretum. Apud Petrum de Castro. Salmananca, 1541.

15.Summa de la doctrina cristiana. A. de Portonaris. Salamanca, 1552.

16.Summulae. In officina ... Ioa[n]nis iunte [sic]. Burgis, 1529.

17.Super octo libros Physicorum Aristotelis comentaría. J. de Junta. Salamanca, c. 1545 .

18.Super octo libros phisicorum Aristotelis quaestiones. J. de Junta. Salamanca, c. 1545.

19.Tratado del amor de Dios. por Blas Roman. Madrid, s.a.

20.Traslado de un Sumario que coligió Domingo de Soto de una Apología hecha por el obispo de Chiapas contra G. de Sepúlveda [atribuida en alguna ocasión, por el resumen que hizo]. Aparece en: disputa entre las Casas Sepulueda. en casa de Sebastián Trujillo. Seuilla, 1552.

Como el de los otros dos intelectuales segovianos de referencia el número de páginas es muy abultado, su calidad grande.

\subsection{Antonio de Herrera}

Fue autor de una obra de tal magnitud que no fue impresa íntegramente en su tiempo ni tampoco editada o reeditada desde el siglo XVII; su producción tiene la cronología que se indica ${ }^{26}$.

${ }^{26} 1582$ Escribió su Historia de.- 1588 Tradujo la Historia de la guerra entre turcos y persianos, de Minadoy.- 1589 Publicó la Historia de María Estuardo.- 1592 Tradujo "Diez libros de la razón de Estado", de Juan Botero.- 1592 Tradujo "Advertencias que los catholicos de Inglaterra embiaron a los de Francia en el cerco de París".- 1598 Fue nombrado Cronista de Castilla.- 1598 Crónica de los Turcos.- 1598 Publica Sucesos de Francia.- 1598 Publicó Información de lo que pasó en Milán.1599 Primera edición de los Sucesos de Milán.- 1600 Censuró "Comentarios de las alteraciones de Flandes, de R. N. Miriteo".- 1601 Publicó la primera parte de su Historia general del Mundo.- 1601 Se trasladó con la Corte a Valladolid.- 1601 Publicó la primera parte de sus Décadas.- 1601 Aprobó la edición de la "República mista", de J. Fernández de Medrano.- 1601 Aprobó la "Historia de las missiones que han hecho los religiosos de la Compañía de Iesus para predicar el Sancto Evangelio en la India Oriental y en los reinos de la China y el Iapon", de L.Guzmán.- 1604 Aprobó la segunda parte del "Romancero General y flor de diversa poesía", recopilación de M. Madrigal.- 1607 Tradujo "Batalla espiritual", del cardenal Fermo.- 1608 Aprobó de la "Historia general de Argel", de D. Haedo.- 1608 Trabajó en su Historia de las Indias.- 1609 Censuró "Grandezas y antigüedades de Cádiz", de J. Suárez Salazar.- 1609 Publicó su segunda edición de Sucesos de Milán.- 1610 Aprobó 
1. Comentarios de los hechos de los españoles, franceses, y venecianos en Italia, y de otras Republicas, Potentados, Príncipes, y Capitanes famosos italianos, desde el año de 1281 hasta el de 1559. Por Iuan Delgado, Madrid 1624. (Dedicatoria a Gaspar de Guzmán Conde de Olivares cuyo escudo consta en la portada).

2. Discursos morales, políticos é históricos inéditos. Imprenta de Ruiz. Madrid, [1804].

3. Elogio a Don Baltasar de Zuñiga Comendador mayor de Leon, del Consejo de Estado, y Presidente del supremo de Italia.

4. Elogio de Vaca de Castro.

5. Exequias de la Reina Doña Margarita de Austria, muerta el 3 de Octubre de 1611. por Diego Diez. Segovía, 1637].

6. Historia de lo sucedido en Escocia, è Inglaterra, en quarenta y quatro años que biuio Maria Estuarda, Reyna de Escocia. En casa de Pedro Madrigal. Madrid, 1589. (Dedicatoria a Diego Fernández de Cabrera y Bobadilla, conde de Chinchón y Alcaide perpetuo de los Alcáceres Reales de la ciudad de Segovia); Otra edición en Manuel de Lyra. Lisboa, 1590.

7. Historia de los sucesos de Francia desde el año de 1585 que començò la liga Catolica, hasta en fin del año 1594... por Lorenço de Ayala. Madrid, 1598 (Dedicatoria a Felipe III).

8. Cinco libros de Antonio de Herrera de la Historia de Portugal, y conquista de las Islas de los Açores, en los años de 1582 y 1583... en casa Pedro Madrigal. Madrid, 1591 (Dedicatoria Luis Carrafa de la Marra, Príncipe de Stillano, casado con una hija de Vespasiano Gonzaga).

de "Historia de la vida del glorioso San Frutos", de L. Calvete.- 1612 Publicó la tercera parte de su Historia general del Mundo.-1612 Aprobó "Hechos de don García Hurtado de Mendoza", de C. Suárez Figueroa.- 1612 Publicó su Tratado, relación y discurso ... de Movimiento de Aragón.- 1612 Firmó su primer testamento.- 1613 Prosiguió sus trabajos de Historia de las Indias.- 1614 Censuró "Historia del gloriosos apóstol Santiago", de H. Oxea.- 1615 Continuó la publicación de las Décadas o Historia de los hechos de los castellanos...- 1615 Tradujo de "Los cinco libros primeros de los Annales", de C. C. Tácito.- 1616 Aprobó la publicación de "Sumario de lo que aconteció los años...", de J. de Mariana.- 1620 Aprobó "Revoluciones cronológicas", de A. Maldonado.- 1620 Aprobó "El enbaxador", de J. Vera y Zúñiga.- 1622 Se publica en Ámsterdam su Descripción de las Indias, en latín, traducida por el propio autor.- 1622 Aprobó "Historia y anales de la ciudad y obispado de Plasencia", de A. Fernández.- 1624 Publicó su Comentarios de los hechos de los españoles, franceses,... 
9. Historia general de los hechos de los castellanos en las Islas i Tierra Firme del Mar Oceano; en quatro Decadas desde el año de 1492 hasta el de 1531; por Iuan Flamenco. Madrid, 1601; Decada quinta a octava. - Ju[an] de la Cuesta. Madrid, 1615.

10.Descripcion de las Indias Occidentales. En la Oficina Real de Nicolas Rodriguez Franco. Madrid, 1725-1730.

Figura 4. Portadilla de una de las crónicas más interesantes, nunca vuelta a editar y menos citada de Herrera

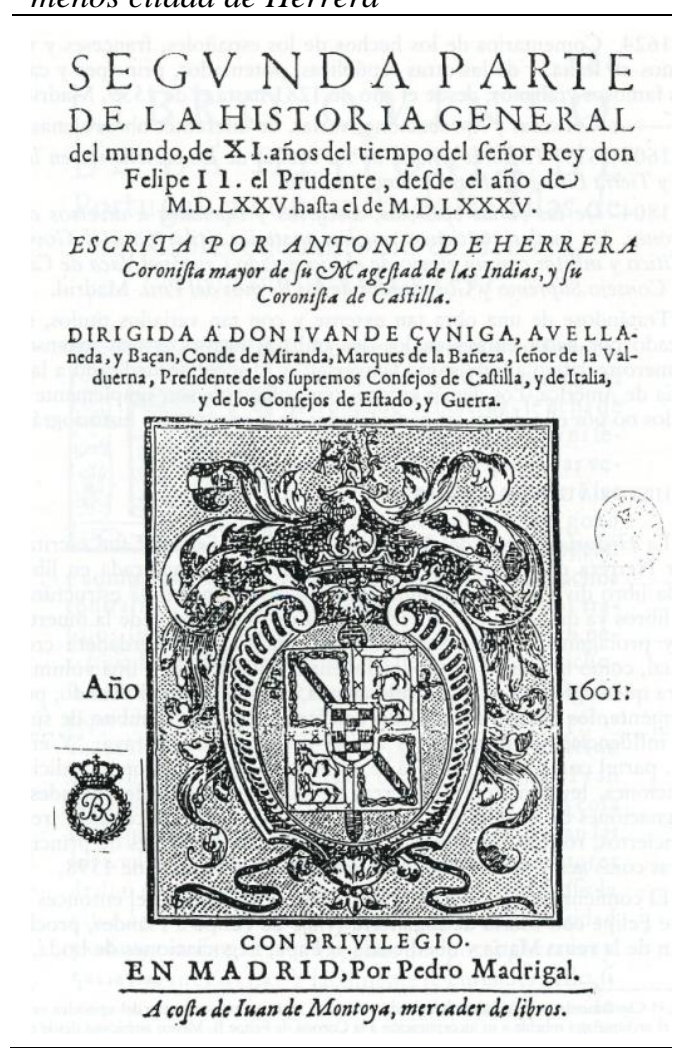

11.Primera parte de la Historia general del Mundo... desde el año de MDLIX hasta el de MDLXXIIII. Por Luis Sánchez, a costa de Juan de Montoya mercader de libros. Madrid, 1601; Segunda parte de la Historia general del Mundo... desde el año de MDLXXV hasta el de MDLXXXV. Por Pedro 
Madrigal (en casa de Miguel Serrano de Vargas), a costa de Iuan de Montoya, mercader de libros. Madrid 1601 (1600); Tercera parte de la Historia general del mundo... desde el año de 1585 hasta el de 1598... por Alonso Martin de Balboa: a costa de Alonso Perez mercader de libros. Madrid, 1612.

12.Informacion en hecho, y relacion de lo que passo en Milan, en las competencias entre las juridiciones Eclesiastica y Seglar, desde el año de 1595 hasta el de 1598. S.1., s.n., s.a. En Madrid c. 1599; por Luis Sanchez, 1609, por cambio de portada.

13.Informacion en el hecho, y relacion de lo que passo en Milan en las competencias, entre las juridiciones Eclesiastica, y Seglar, dede el año de 1595 hasta el de 1598. En Madrid: por Luis Sanchez, 1609.

14.Tratado, relación y discurso histórico de los mouimientos de Aragon sucedidos en los años de mil y quinientos y nouenta y vno, y de mil y quinientos y nouenta y dos: y de su origen y principio hasta que... Filipe II... compuso y quieto las cosas de aquel Reyno - En Madrid: en la Imprenta Real, 1612.

Asimismo, Herrera ofrece otros textos preliminares a las obras de otros autores (censuras y aprobaciones) ${ }^{27}$ así como traducciones ${ }^{28}$; asimismo obras de Herrera

${ }^{27}$ Alfaro, G.: Vida del Illustrissimo Sr. D. Francisco D. Reynoso, obispo de Cordoba...; Calvete, Lorenzo: Historia de la vida del glorioso San Fructos patrón de la ciudad de Segouia..; Fernández, Alonso: Historia y anales de la ciudad y obispado de Plasencia; Fernández de Medrano, Juan. Republica mista...; Guzmán, Luis de. Historia de las missiones que han hecho los Religiosos de la Compañia de Iesus, para predicar el Sancto Euangelio en la India Oriental, y en los Reynos de la China y Iapon; Haedo, Diego de. Topographia é Historia general de Argel: repartida en cinco tratados..; Horozco, Agustín de. Discurso historial de la presa que del puerto de la Mamora hizo la Armada Real de España; Maldonado, Alfonso (O.P.). Resoluciones cronologicas..; Mariana, Juan de: Sumario de lo que acontecio los años adelante; OJEA, Hernando de (O.P.). Historia del glorioso Apostol Santiago patrón de España...; Río, Martín Antonio del: Comentarios de las alteraciones de los Estados de Flandes, sucedidas despues de la llegada del señor don Iuan de Austria a ellos, hasta su muerte; Segunda parte del Romancero General y Flor de diuersa Poesia, recopilados por Miguel de Madrigal; Suárez de Figueroa, Cristóbal. Hechos de don García Hurtado de Mendoza, quarto Marques de Cañete...; Suárez de Salazar, Juan Bautista: Grandezas, y antigüedades de la isla y ciudad de Cádiz...; Vera y Zúñiga, Juan Antonio. El Enbaxador; por otra parte José Simón Diaz, Bibliografía de la Literatura Hispánica, t. 11, n. 4700 y 4701, cita poesías sueltas de Herrera (respectivamente en: Ariz, L. Historia de las grandezas de... Auila. - Alcalá..., 1607, en prelimimares; y en: Anfiteatro de Felipe el Grande... - Madrid..., 1631, h. 37r.), consideramos que se trata de un error.

${ }^{28}$ Advertencias que los catolicos de Inglaterra escriuieron a los catolicos de Francia, tocantes a las presentes reboluciones, y cerco de Paris (del francés); Diez libros de la razón de Estado con tres libros De las causas de la grandeza, y magnificencia de las ciudades / de Iuan Botero (de Italiano); 
fueron traducidas a otros idiomas: francés, inglés, alemán, holandés y latín. Y existen no pocos manuscritos de Antonio de Herrera en la Biblioteca Nacional de España $^{29}$ y en la Biblioteca Colombina.

\subsection{Diego de Avendaño}

También escribió copiosamente, alguno de sus tomos menos notorios presenta novecientas páginas -Mysterium fidei-, pero hay una obra que interesa aquí especialmente, su Thesaurus, escrita en seis tomos aunque aparentemente pudiera parecer que se presenta en dos volúmenes. Las demás tienen su importancia pero en otra problemática. Además de otros trabajos que se le han atribuido, sus títulos quedan reseñados a continuación:

1. Thesaurus indicus Tomus primus, apud Iacobum Meursium, Antuerpiae 1668.

2. Thesaurus indicus Tomus secundus, apud Iacobum Meursium, Antuerpiae 1668.

3. Auctarium indicum (tomus primus), apud Iacobum Meursium Antuerpiae, 1675 [ $3^{\circ}$ del Thesaurus indicus] .

4. Auctarium indicum (tomus secundus), apud Iacobum Meursium Antuerpiae, 1675 [4 $4^{\circ}$ del Thesaurus indicus].

5. Auctarium indicum (tomus tertius), apud Iacobum Meursium Antuerpiae, 1675 [5 $5^{\circ}$ del Thesaurus indicus].

6. Auctarium indicum (tomus quartus), apud Hieronymum Verdussen. Antuerpiae, 1686 [6 $6^{\circ}$ del Thesaurus indicus].

7. Amphiteatrum Miseridordiae Expositio Psalmi LXXXVIII. Sumptibus Boissat \& Georgia Remmeus. Lugduni 1666.

8. Problemata Theologica (tres tomos) Apud Engelbertum Gymnicum. Antuerpiae, 1668.

Historia de la guerra entre turcos y persianos, escrita por Iuan Tomas Minadoy (de italiano); Batalla espiritual y arte de seruir a Dios, con la Corona y Ledania de la Virgen Maria (de italiano); Los cinco primeros libros de los Annales de Cornelio Tácito: que comienzan desde el fin del Imperio de Agusto [sic] hasta la muerte de Tiberio (de latín); etc.

29 Inventario general de manuscritos de la Biblioteca Nacional. General de Archivos y Bibliotecas. Madrid, 1953-1988. También: PAZ, J. (1933). Catálogo de manuscritos de América existentes en la Biblioteca Nacional. Madrid : [s.n.]. 
9. Cursus consummatus sive Recognitiones theologicae, expositivae scholasticae et morales... Hieronymum Verdussen. Antuerpiae, 1686.

10.Epithalamium Christi et sacrae Sponsae se explanatio psalmi quadragesimiquarti. Laurentii Anisson. Antuerpiae 1653 (hay otra edición de Lyon 1643= comentario de 800 páginas al salmo 44 ciato en Thesaurus)

Figura 5. Marca de impresión de la obra de

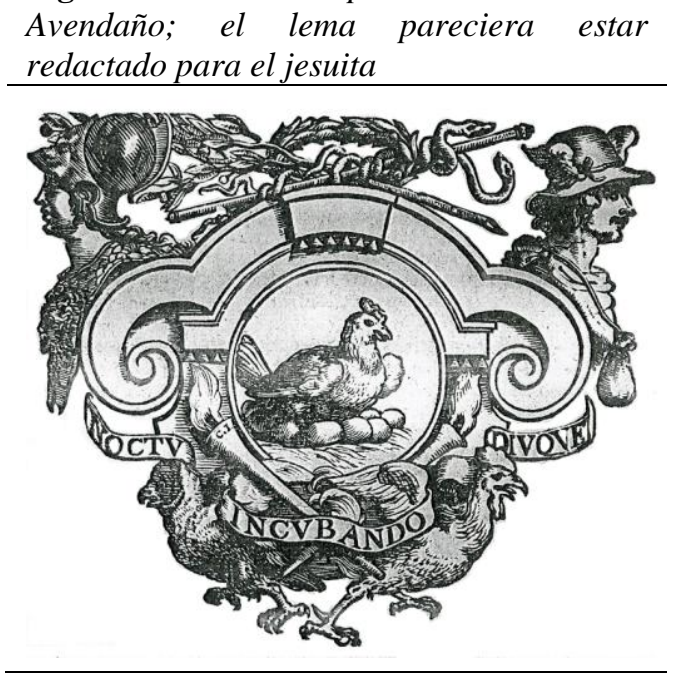

11.Expositio Psalmi LXVIII.

12.Relación de la Congregación Provincial. Perú $1674^{30}$.

13. Cartas annuas de la Provincia del Perú De la Compañía de Jesús, de los años 1663 a 1665, al PR. General de la Compañía ${ }^{31}$.

14.Mysterium fidei in ipsius Sacro et canonico canone celebratum (Firmado por el autor en 4, septiembre, 1681).

\section{MATERIA DE ESTUDIO COMÚN, RESULTADOS DISPARES}

Materia común de confluencia entre estos tres intelectuales se halla en el elemento americanista, cada uno de ellos, con incursiones en otra temática diversa;

\footnotetext{
${ }^{30}$ Manuscrito perdido en la Biblioteca Nacional de Lima.

${ }^{31}$ Manuscrito perdido en la Biblioteca Nacional de Lima.
} 
la divergencia principal se halla en el enfoque, en sus objetivos, en su metodología, en sus procedimientos y, también, en sus resultados. Soto y Avendaño tienen una orientación teológica, filosófica que se diferencia de la predominantemente histórica de Herrera; asimismo el énfasis puesto en aspectos de ética de los primeros es divergente con el característico estilo descriptivo del cronista. El historiador lo es de los españoles, a los que llama, intencionadamente, castellanos; es compilatorio y no tiene inconveniente en comprometerse en el relato; el dominico es un filósofo, un pensador, que pone el acento en temas que afectan al europeo, que repercuten en el nativo en toda la población en Indias; el jesuita es un pragmático que está sobre el terreno americano, vive los problemas y se ve implicado en ellos. Mientras que Soto es un especulativo, Avendaño es un empírico; no cabe duda que todos ellos muestran notas de las dominantes en los otros dos.

\subsection{Domingo de Soto}

Respecto al tema americanista pesaba la cuestión de los derechos y deberes para con los indios; el tema había dado lugar a diversas controversias, algunas particularmente agrias. Los propios Reyes hacían consultas a los teólogos, forzándolos "a revisar todo ese mundo de principios y de ideas del campo teológico-jurídico, que venían imperando en Europa"32; su majestad cesárea volvió a echar mano del ilustre teólogo Soto ante la controversia las Casas y Sepúlveda. La "Junta de los Catorce" en Valladolid (1550), compuesta por letrados, teólogos y juristas, tuvo como árbitro a Domingo de Soto; él ejerció de relator; su sumario fue impreso (Sevilla 10, septiembre, 1552). El segoviano facilitó que las votaciones fueran favorables a los indios; la polémica sigue en pie. Su gran prestigio le hizo merecedor de un lema que ensalza tanto a Soto como al conocedor de su obra.

Aristotélico-tomista, su relación con el tema de la herejía y del Tribunal del Santo Oficio fue importante; su participación en la cuestión del arzobispo Carranza es lo más difundido ${ }^{33}$. A título de ejemplo, sus obras se ven exaltadas por las ediciones de que fueron objeto, treinta en el mismo siglo XVI y la extraordinaria difusión alcanzada por su obra "De Iustitia et Iure" (1553-54), por ejemplo, que también se editó en Lyon, Amberes, Venecia, Medina del Campo, Madrid...

32 Soto, D. (1967). De iustitia et iure libri decem (De la justicia y el derecho en diez libros). Introducción histórica y teológico-jurídica por Venancio Carro; versión española Marcelino González Ordóñez. Madrid: Instituto de Estudios Políticos, Tomo primero, p. XVI.

33 TellecheA, J. I. (1972). El Catecismo del Arzobispo Carranza. Madrid: Fundación Universitaria Española. 
Figura 6. Portada de De natura et gratia, de Domingo de Soto

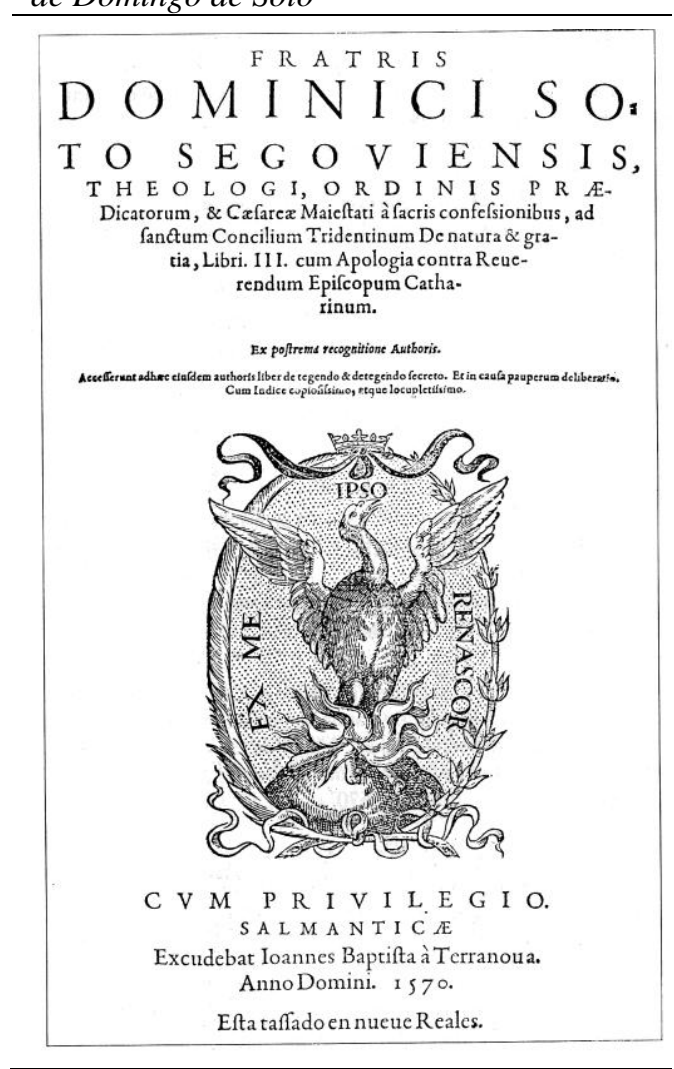

Además en este tratado se demuestra que el teólogo-jurista tenía un importante conocimiento de la vida económica de su tiempo al analizar y examinar una serie de cuestiones tan interesantes como los precios, moneda, mercados, monopolios, contratos, intervención del Estado, gastos públicos, tributos, etc. ${ }^{34}$. Ahora bien, se puede asegurar que "al expresar su voto procedía con libertad, aun a riesgo de indisponerse con los demás" y al igual que a su maestro el Padre Vitoria, se le tenía por "integérrimo e insobornable" ${ }^{35}$.

${ }^{34}$ Velarde Fuertes, J. Op. cit.., [nota 2], pp. 445-455. Segovia.

${ }^{35}$ Heredia, B. de (1961). Domingo de Soto..., p. 599. BACIERo, C. (1992): «Domingo de Soto y los primeros jesuitas del Perú». En Cuesta, D. (edit. y dir). Proyección y presencia de Segovia en América. [nota 2]. Madrid: Deimos, pp. 481-498. BRufau PRATS, J. (1960). El pensamiento político 


\subsection{Antonio de Herrera}

Las Décadas ${ }^{36}$ no podían ser un producto sencillo, breve ni complaciente para todos. Pero con independencia de estos juicios bienintencionados y sin duda con fundamento hay algunos datos objetivos sobre la consideración que los coetáneos tuvieron sobre las Décadas. Nos referimos a las ediciones y traducciones realizadas de esta obra de Herrera, total o parcialmente. En español: 1601-1615, 1726, 1728 ${ }^{37}$, 1729-1730 ${ }^{38}$, 1934-1957, y 1992; en latín: 1622,1623 y 1624; en francés: 1622, 1660 y 1671; en alemán: 1623; en holandés: 1706; y, en inglés: 1724, 1725-1726 y 1743.

Ya se sabe que para su labor historiadora apareció ante el cuellarano un espacio geográfico caracterizado por la inmensidad y un lapso cronológico, que puede ser considerado abarcable para su trabajo pero que ofrece tales notas de intensidad que constituye medio siglo de enorme complejidad y riqueza ${ }^{39}$; podría decirse que Herrera escribe justamente sobre el período coincidente con la biografía de Domingo de Soto. Hay datos suficientes para verificar que Herrera no perdió el tiempo, como podría concluirse por la propia finalización (dos décadas después de iniciada) de tan voluminosa obra, que es de por sí suficiente testimonio, son, entre otros los que se constituyen en indicios racionales a través de documentación de algunos gastos originados por el desarrollo de los trabajos de edición e impresión de las Décadas.

Los contenidos de las Décadas quedan suficientemente explicados por su título, "Historia general de los hechos de los castellanos", bien escogido por el autor, en que se halla explícitamente expresada la intencionalidad de Herrera, nuevamente explicitada en la dedicatoria de la Década primera; evidentemente sería un error

de Domingo de Soto y su concepción del poder. Salamanca: Universidad de Salamanca. HeRnÁndeZ, R. (1992). Americanismo lascasiano de Domingo de Soto. En Cuesta Domingo (edit. y dir) [nota 2], pp. 467-480. CASAS, B. de las Obras completas. Ed. de P. Castañeda Delgado. 14 v. Madrid: Alianza

${ }^{36}$ HerRera y TORDESILlas, A. de (1934). Historia general de los castellanos en las islas...de Herrera: edic. de Ballesteros Beretta, "Proemio", I: IX-LXXXVIII. Madrid, 1934; la última edición íntegra de Cuesta Domingo. UCM. Madrid, 1991. Cuesta Domingo, M. del P. «Antonio de Herrera y su aportación a la historiografía». En CUESTA DOMINGO (edit. y dir) [nota 2].

${ }^{37}$ Con las láminas de Teodoro de Bry.

${ }^{38}$ Con crítica a la edición iluminada por Bry, la de Amberes 1728.

${ }^{39}$ Aunque con referencias posteriores a la fecha considerada terminal en su trabajo (1554). Es evidente que Antonio de Herrera comienza a escribir cuando los últimos acontecimientos, "hechos de los castellanos", habían sucedido 42 años antes; en aquel entonces él mismo contaba un lustro en su trayectoria vital; el descubrimiento colombino tuvo lugar a más de un siglo de distancia y el propio Herrera, como se ha indicado, nunca es tuvo en América. 
pretender hallar en la obra cualquier dato o materia ajena a lo que su título indica. Antonio de Herrera redactó, y es oportuna la redundancia, una historia de los hechos de los castellanos. Fundamentalmente, se trata de lo que el autor dice: hachos de los castellanos, más allá del medio natural, cuya descripción hace aparte, fuera de contexto, por encima del mundo indígena; dando la prioridad al tiempo. De modo análogo actúa Herrera en la Historia General del Mundo aunque en esta obra el período elegido es el anual, como dice el propio autor: "distinguiendo los libros en años, conteniendo cada libro lo sucedido en un año" ${ }^{40}$.

Tampoco se trata de una historia cuyo objetivo primordial fuera comprender y valorar lo sucedido, fundamentalmente es descriptiva, de hechos cuyo protagonismo se halla en los castellanos ${ }^{41}$. Esa preocupación que le hace dar supremacía a los hechos camufla la claridad y comprensión de su obra que, a caballo entre la Historia y la Crónica, se decanta hacia la última, cuyo marco clave es el personalismo y la temporalidad. Y, sin embargo, el cronista es un historiador. No vivió el tiempo de los acontecimientos que relata, por lo mismo no se sintió implicado en ellos ni muestra un apasionamiento por su desarrollo; dispone de materiales distantes por los que se halla sin compromiso alguno. Tal es así que como historiador mantiene su criterio por encima de eventuales inconvenientes que, en ocasiones, fueron reales ${ }^{42}$. El magisterio de Tácito, Livio, Cassio, Tasso, Adriani, Mendoza y otros se manifiesta en Herrera como historiador y a lo largo de las Décadas y otras obras de carácter histórico hace frecuentes referencias al efecto, como tenemos ocasión de apreciar.

De ahí el sobrenombre de Décadas. Por cuanto la coordenada dominante es ese tiempo, el decenio; a él queda supeditado toda la unidad del conjunto. La sincronía en la descripción de los hechos rompe, frecuentemente, la línea narrativa y obliga al lector a pasar de un "libro" a otro e incluso de una "Década" a otra para conocer la exposición de los acontecimientos. Tal es así que, como ya hemos indicado en otros lugares, es factible una lectura alternativa de la Historia herreriana, diferente en el orden a la establecida por el autor. Una lectura en secuencia diacrónica, al hilo de los hechos; una lectura más fácil, comprensiva e, incluso, dotada de mayor lógica.

Sus Décadas sitúan un marco geográfico en el más estricto sentido de la palabra en tanto materia que ayuda a comprender la historia localizando los lugares

\footnotetext{
${ }^{40}$ HerRerA. Historia General del Mundo, $2^{\mathrm{a}}$. parte. [nota 17]

${ }^{41}$ Herrera reitera el término castellanos, evitando (intencionadamente) el de "españoles" por considerarlos idénticos.

${ }^{42}$ AGI, Patronato, 170; Codoin, XXXVII.
} 
principales, ofreciendo la configuración del territorio como teatro de operaciones en que tuvieron lugar los hechos, que es lo importante para el autor. La Descripción de Herrera culmina la tradición acumuladora de datos que desde el primer viaje colombino se ofrece al lector a través de las crónicas y tratados de náutica pero sobre todo mediante la confección de manuales más o menos detallados, más o menos completos: las obras de Fernández de Enciso, Alonso de Chaves, Alonso de Santa Cruz y Juan López de Velasco además de la cartografía han sido las fuentes en que Herrera bebió para confeccionar su propia Descripción de las Indias e incorporar sus catorce mapas de América y Extremo Oriente. La crónica americana de Herrera usa y cita, al estilo de Avendaño, infinidad de fuentes no teniendo empacho en dejar claro la credibilidad o descrédito que le merece alguna de ellas, incluso las que conoce y rechaza sin mayor preocupación por prejuicio alguno. Así lo indica el propio Herrera ${ }^{43}$ haciendo un listado de las autoridades en que se basó aunque "dejando aparte muchas cosas que los referidos autores han dicho por no poderse verificar con escrituras auténticas"; entre los autores que señala están Anglería, Benavente, Hernando Colón, Ojeda, Enciso, Fernández de Oviedo, Gómara, Cieza, Alvar Núñez, Bernal, las Casas, Cervantes de Salazar, Jerez, Jiménez de Quesada, Pedro Pizarro, Cortés, Nuño de Guzmán, Diego Fernández el palentino, Zárate, Ercilla y otros. El propio Cronista no lo oculta y existen pruebas al efecto ${ }^{44}$, pero también es cierto que hizo buen uso de otra mucha documentación, incluida la que podemos denominar así, strictu sensu.

Pero, sobre todo, Herrera utilizó con profusión los documentos procedentes de los libros de Cámara y otros documentos del archivo del Consejo de Indias; una abundancia de excelentes fuentes y de la obligatoriedad de su uso que le imponían las disposiciones legales surtieron su efecto; algunas obras son conocidas gracias a la difusión de ciertos originales por este autor, unos manuscritos que solo han sido hallados en el siglo XX y otros, en el presente, todavía no.

Herrera reiteró el uso que hizo de los "papeles, relaciones, cartas y escrituras que había en la Cámara Real y archivos reales" ${ }^{45}$ e insiste ${ }^{46}$ : "Cuando el Rey

${ }^{43}$ En los "principios" que anteceden a su Descripción, pág. 122.

${ }^{44}$ En PAZ, J. (1992). Catálogo de manuscritos de América existentes de la Biblioteca Nacional. $2^{\mathrm{a}}$ ed. rev. por C. Olaran y M. Jalón. Madrid, figura con la signatura: Res. 21 a 23, la Historia general de las Indias de B. de las Casas. En la descripción realizada por el archivero puede leerse, entre otros datos: "Al final de éste hay una nota firmada por el licenciado Baltodano, del Consejo de las Indias, en que consta que este manuscrito fue uno de los que se entregaron a A. de Herrera para escribir la Historia de las Indias, conforme a la Real Cédula de 24 de septiembre de 1597".

${ }^{45}$ Década $V^{\mathrm{a}}$, libro II ${ }^{\mathrm{o}}$, capítulo 4.

${ }^{46}$ Década VI' , libro III ${ }^{\circ}$, capítulo 19 (parte final). 
Nuestro Señor don Felipe Segundo, de gloriosa memoria, me mandó escribir esta General Historia, ordenó que me diesen los papeles que había en su real Cámara ${ }^{47}$ y en la guardajoyas y todos los que tenía su Secretario Pedro de Ledesma, adonde estaban los que enviaron a Su Majestad el Obispo-Gobernador de Nueva España, don Sebastián Ramírez y los Visorreyes don Antonio de Mendoza y don Francisco de Toledo, a fin de hacer historia;

Figura 7. Portadilla de una Década de Herrera con la efigie de algunos protagonistas e imágenes de inspiración en los códices

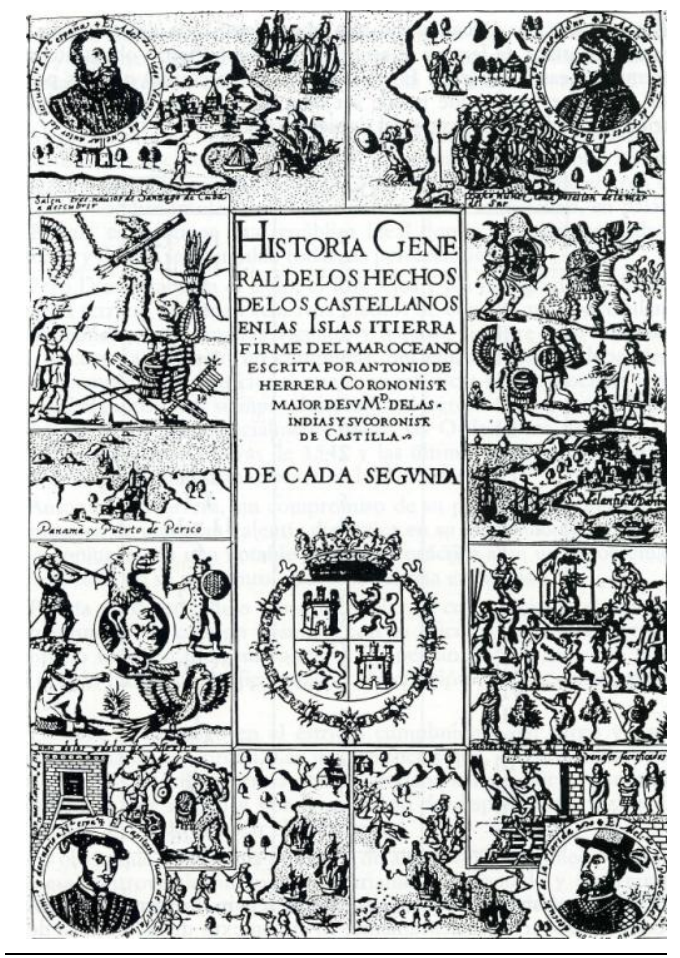

Sin embargo hay que admitir que es este el punto sobre el que más se ha polemizado, innecesariamente, en la obra de Herrera, el que más y más acerbas críticas ha suscitado y el que de forma más apasionada ha sido expuesto. Su

${ }^{47}$ Antonio de Herrera incluyó su voluntad de que fueran devueltos en su segundo testamento. 
metodología fue la habitual en la época, y aún en otras anteriores; el uso de las fuentes se realizaba según el interés que tuvieran para los objetivos del autor y para su obra, citando, muchas veces de memoria, con imprecisiones y, por lo mismo, con inevitables errores. Son exagerados, pues, los calificativos de plagiario para Herrera, como lo hubieran sido para Las Casas, por ejemplo; qué no podría decirse de la utilización de las Décadas de Herrera como fuente por otros escritores: véase el caso de Peguero ${ }^{48}$ o en Solórzano Pereira. Algunos de los juicios, ya clásicos, emitidos sobre Herrera y su obra resultan absolutamente ilustrativos: Juan Bautista Muñoz dejaba traslucir su valoración del cronista no otorgándole mayor valor intelectual que el puramente artesanal

no hizo más que juntar retazos y extractos, a manera de quien dispone por el orden de los años y aun de los meses y días las narraciones tomadas de todas partes, como materiales para escribir una historia a la par que expresaba opiniones más favorables por fortuna que era hombre docto y juicioso; sino, fueran innumerables los errores de estas sus memorias, según la precipitación con que las ordenó...Los libros de registro y demás papeles del ministerio y consejo, aunque disfrutando de corrida y con menos utilidad, diéronle bastante luz para conocer lo indigesto y perturbado de las narraciones de Mártir, la inexactitud, la credulidad, las fábulas de Oviedo, sus copiantes e imitadores... ${ }^{4}$.

No han faltado las opiniones contradictorias que, con frecuencia, han sido publicadas. Por un lado la insistencia en el plagio; por el otro el positivo valor de la obra $^{50}$. Jiménez de la Espada analizó el uso que Herrera hizo de la crónica de Cieza $^{51}$; y Barros Arana, por su parte, llegó a afirmar que don Antonio tuvo a la

48 Peguero, L.J. (1975). Historia de la conquista de la isla española de Santo Domingo; trasumptada el año de 1762. Edición y notas de P. J. Santiago. Santo Domingo: Museo de las Casas Reales.

49 Ibidem.

50 Así, por ejemplo, CARBIA, R. (1940. La crónica oficial de las Indias. Buenos Aires) dice que Herrera somete sus aseveraciones a un cuidadoso análisis y a una discriminación que hoy mismo sorprende; no deja de ser sorprendente tanta consideración en la pluma de Carbia. Por su parte FUETER (1953). Historia de la historiografía moderna. Buenos Aires: Nova, califica a las Décadas como la "Vulgata de las tradiciones de los descubrimientos". Con posterioridad han salido a la luz numerosos trabajos historiográficos los de R. Kagan pero la cita pormenorizada cae fuera de este título.

51 Contradictoriamente, JimÉnEz DE LA EsPADA, M. (1881). Relaciones geográficas de Indias. Madrid: Ministerio de Fomento, critica que Herrera modifica lo expresado en el original por Cieza, corrompiendo la puridad histórica. Pero, si cambiaba palabras e incluso conceptos del cronista extremeño, cómo tildar de puro plagiario al cronista cuellarano, se pregunta Ballesteros (Proemio, 
vista muchos materiales inéditos que "copio o plagió en muchos y largos pasajes" 52 ; sin embargo no ocultó asimismo, que era una práctica "común en sus contemporáneos, como lo prueba el padre Torquemada, cuya obra es en gran parte un plagio descarado". No obstante, la opinión de Barros es muy positiva para Herrera, pues "este procedimiento es el que constituye el valor de su libro porque aunque adolece de algunos descuidos de detalle...Su obra merece ser citada siempre como una autoridad contemporánea de los sucesos que narra, por más que haya sido escrita mucho más tarde".

Estos testimonios, que no son sino unos ejemplos antiguos de lo que ha venido reiterándose a lo largo del tiempo, sintetizan suficientemente las versiones que corren sobre la obra herreriana; la Historia del Cronista Mayor se destaca nítidamente por ese claroscuro de la incorporación de manuscritos de otros (hábito generalizado) y validado precisamente por su uso ${ }^{53}$. Uno de sus últimos editores, González Barcia no tiene inconveniente en afirmar que las falsas e impertinentes oposiciones antiherrerianas, eran como las manchas que fingen en el sol los astrónomos ofuscados de su luz"; y, finalmente, Menéndez Pelayo ${ }^{54}$, manifestó una opinión muy favorable (quizá resulte hiperbólica) para el cuellarano: "como hombre de discreción y gran juicio, mejoró siempre los originales de que tan libremente se servía, mereciendo por ello la loa de compilador metódico y elegante, fácil y agradable de leer siempre, útil hoy mismo, y utilísimo cuando se desconocían los documentos originales...sus Décadas que, como obra de conjunto e historia general de la América española quizá no han sido superadas hasta el presente, por más que la gloria de Herrera, conocidos ya los originales, deba repartirse hoy entre muchos participantes".

Párrafo aparte merece otra obra de Herrera, la Historia General del Mundo en tiempos de Felipe $I I^{55}$; una verdadera crónica anual, como un diario de acontecimientos que da lugar a una voluminosa obra que engloba lo que su título abarca, considerando los hechos del reinado del "prudente" en el ámbito de su área de influencia; acontecimientos que el propio autor subraya: "Y en ella [2 2 . parte] como en la primera se verán tumultos, rebeliones, sediciones, traiciones,

LXXI). Última edición importante de las Obras completas de Pedro CieZA De León (1985), la realizada (en 2 vols.) por Sáenz de Santa María. Madrid: Instituto Gonzalo Fernández de Oviedo.

${ }^{52}$ Ibidem.

${ }^{53}$ Por encima de los errores en que incurrió como consecuencia del origen múltiple de su información y la rapidez en la confección de su obra.

${ }^{54}$ Antología de estudios y discursos literarios. (2009) Ed. de M. Crespo. Madrid: Cátedra , pp. VII, 73 .

${ }^{55}$ En tres partes y cada una de ellas estructurada en libros y cada libro dividido en capítulos. 
levantamientos, guerras de pueblos, presas de ciudades, expugnaciones de fortalezas y castillos, sacos de lugares, incendios, treguas, conciertos, roturas de paces, matanzas de gentes, muertes de príncipes y otras cosas acontecidas" ${ }^{56}$ desde el años de 1575 hasta el de 1598. Se inicia en 1554 (libro I) con el casamiento del entonces príncipe Felipe con María de Inglaterra (viaje de Felipe a Flandes, proclamación de la reina María y obediencia al Papa, negociaciones de boda, actividades de la reina, guerras en Europa y el Mediterráneo, etc.). De tal modo se suceden los años (1555, libro II; 1556, libro III; 1557, el IV; 1558 el V; etc.etc., hasta 1598). Los contenidos que describe hacen referencia a África (Túnez y la Goleta y Preste Juan), a Asia (Persia, Armenia, Arabia, Tartaria, Malaca), al Atlántico y Mediterráneo, al Pacífico (Filipinas, Japón, islas Salomón, Legazpi) y a las Indias (Santo Domingo, Cartagena, Ursúa y El Dorado, los Ingleses en el Pacífico, "Francisco Draque", Pedro Sarmiento y Diego Flores, la cuestión del estrecho de Magallanes, etc.). Como sucediera en las Décadas, la metodología y fuentes es análoga, y los autores que menciona además de la propia documentación que hubo de manejar constituyen un testimonio fehaciente de la capacidad de trabajo de Herrera ${ }^{57}$. Una obra cuya magnitud ha sido impedimento para una posterior edición que, estuvo a punto de realizarse en 2003.

\subsection{Diego de Avendaño}

Avendaño era portador de algunos tópicos característicos a su llegada a América; por ejemplo sobre los enemigos de España, países hostiles a los que considera en su papel, sin particular antipatía; dos ejemplos estarían constituidos por los moros, en guerra permanente, y los alemanes a los que los trata condescendientemente por aquella común pertenencia a un mismo imperio. $\mathrm{Si}$ hubiera que buscar algunos rasgos de incompatibilidad se hallarían con quienes considera verdaderamente enemigos, los holandeses, franceses e ingleses.

\footnotetext{
${ }^{56}$ HERRERA: Historia General, dedicatoria, $2^{\text {a }}$ parte.

${ }^{57}$ En las dos primeras partes son los siguientes: Juan Botero y sus Relaciones; fr. Faustino Tasso, Sucesos de nuestros tiempos; Guillermo Rosseo, De iustita retentione; Nicolás Sandero; fr. Gerónimo Polini, Historia de Inglaterra; Gilberto Genebrardo; Lorenzo Surio, Comentarios; León Bélgico, Historia de Flandes; Bernardino de Mendoza, Comentarios; César Campana, Historia General; Felipe Cauriano, Sobre Corneli Tácito; Juan Tomás Minadois, Guerra de Turcos y Persianos; Gerónimo Cadena, Vida de Pío V; Antonio Posevino, Moscovia; Fadere Sacro, Folleta; Gerónimo Fraqueta; Juan Lorenzo Anania, Cosmografía; Natal Conte, Historia General; Mambrino de Rosseo, Historia General (V); Martín Cormero Polaco; Miguel Abisselt, Guerra de Colonia; Juan Nicolás Dolón, Compendio de Historia Universal y Historia de Hungría; Ascanio Centorio, Guerra de Transilvania; Jesuitas, Cartas de Japón; Samuel de Lis, Ultimas revueltas de Francia; Andrea Filopatro, Respuesta al edicto de Inglaterra; Mercantonio Ciapi, Vida de Gregorio XIII, etc. En la tercera y última parte Herrera se apoyó en la documentación existente.
} 
El segoviano a su llegada a Perú quedó impresionado por una problemática social tan alejada de los ámbitos de su formación y procedencia. Fue adaptándose hasta considerarse un verdadero peruano, valga la expresión, y tomar partido por los desfavorecidos, por la condición "miserable" del indio, en el sentido que lo maneja el prof. Castañeda. La relación con Solórzano Pereira consolidó su formación; su carácter jesuítico le hizo apreciar la obra de las reducciones del Paraguay a mayor gloria de la Compañía ${ }^{58}$.

$\mathrm{Su}$ obra cumbre, el Thesaurus, está escrito en un latín excelente, elegante, barroco y ampuloso, con un profundo conocimiento filológico y con ribetes de ironía que, juntamente con el inconmensurable volumen de su obra, constituyen una de las mayores dificultades para que en el siglo XXI aún no haya sido traducida por completo ni difundida suficientemente, si se exceptúan los encomiables trabajos de Castañeda Delgado y Muñoz García, cuya dedicación es tanto más loable.

Podría decirse que la investigación sobre la obra de Avendaño exige tanto tiempo y dedicación como empleó su autor en la realización, que no fue escaso. Un esfuerzo continuado que llevó a término cuando había vivido casi medio siglo en Indias y se veía al final de su vida, "próximo a la eternidad"; una obra que se presenta cual réquiem, como testamento espiritual; persiguiendo un fin utilitario, el bien común, con estilo llano y directo, rápidamente y con la brevedad precisa dentro de la magnitud del trabajo. Consecuentemente se aprecia un rumbo menos jurídico que moral como exige un asesor de conciencias sobre materia americana; como conviene a una obra que se dedica al Consejo de Indias. No es exagerado aceptar que se convirtió en un genuino representante del pensamiento filosófico del siglo XVII en Perú ${ }^{59}$ por más que tan amplio escrito pueda mostrar puntos débiles, especialmente si son observados por la hipercrítica del siglo XX-XXI.

Su Thesaurus muestra una erudición, una profusión de referencias a autoridades que ha contribuido sobremanera a cualquier edición crítica; las referencias muestran el manejo de numerosos autores, empezando por Acosta, pero también textos de las bulas, de los concilios, del Corpus iuris civiles y Corpus iuris

${ }^{58}$ Grijalva, F. (1869). Vida del P. Diego de Avendaño. Lima, 1869; Castañeda Delgado, Paulino (1992). «El segoviano P. Diego Avendaño: un teócrata moderado, ecléctico y tardío». En CUESTA DOMINGO (edit. y dir) [nota 2], pp. 359-396..

${ }^{59}$ Ver HeRnÁNDEZ APARICIO, P.: «La doctrina de Avendaño sobre los repartimientos de Indios», en Cuesta Domingo (edit. y dir) [nota 2], pp. 411-422. Segovia, 1992; LosAdA, A. (1992): «El jesuita segoviano Diego de Avendaño, defensor de los negros en América», en CuESTA D. (edit. y dir) [nota 2]: 359-396. Segovia, 1992; MUÑOZ GARCÍA. [nota 20] Introducción, 54-55. 
canonici. La resultante, la magna obra está formada por dos tomos más cuatro como se ha visto oportunamente; dos del Thesaurus estrictamente titulado más cuatro del Actuarium que son numeran como volúmenes tercera al sexto.

Las materias tratadas por Avendaño son de indiscutible interés; basta con leer los índices de cada tomo, organizado en títulos y capítulos, para hacer una valoración sucinta, como aquí se exige; si se observan los títulos, se aprecia el tratamiento a los derechos y obligaciones de los Reyes, de los Virreyes, de los oidores y funcionarios, etc.

De los primeros planteándose el derecho real sobre los indios y a partir de una respuesta teocrática, positiva, se desencadena toda una síntesis de una doctrina largamente debatida en la España del siglo XVI sobre matizaciones entre herejes e infieles, el carácter misional de la donación, la exclusión de extranjeros, las actitudes premiales a los protagonistas, los beneficios eclesiásticos, etc. Asimismo acerca de cuestiones eclesiásticas de diversa índole, sobre lo que insistirá más adelante, y sobre el trabajo y la esclavitud ${ }^{60}$, cuestiones morales sobre el trabajo indígena y su tributación, temas de conciencia en la administración, ordenanzas y consejeros.

Otros temas interesantes en la obra de Avendaño hacen referencia a la figura del Virrey, sus obligaciones de cumplimiento de la justicia en todo orden de asuntos y, por lo mismo, en lo que afecta a los jueces y venta de oficios. Si se pone atención en la temática jurídica indiana, audiencias, oidores y alcaldes, se vuelve a hacer un recorrido por las cuestiones relativas a sus funciones, obligaciones y hasta los horarios; unos asuntos que son minuciosamente atendidos por el autor que no olvida cuestiones como la boda de las autoridades dentro de su circunscripción, asuntos de contrabando y navíos, de diezmos, expolios y recursos.

Del mismo modo se pone atención en los oidores regios o senadores de la Real Chancillería de Indias y la conveniencia de sobriedad de vida, actitud ante los regalos, beneficios eclesiásticos y diezmos, funerales, expolios, bienes de difuntos, fiscalidad, alcaldes, escribanos, etc. La administración y control de cuentas, tesoros de Indias y derechos arancelarios, incluidas las perlas, piedras finas y otros, el azogue, etc. Bienes diversos, vacantes, obras pías, ab intestato y su prescripción, de naufragio, de eclesiásticos, de alcabala, de almojarifazgo y avería, decomisos y confiscaciones, oficios venales, tabernas, monopolio de la nieve, del papel sellado y de la Bula de cruzada, y un largo etcétera que se distribuyen en los sucesivos y

${ }^{60}$ LÓPeZ García, J. (1982). Dos defensores de los esclavos negros en el siglo XVII. Maracaibo: Biblioteca Corpozulia. 
múltiples capítulos del Thesaurus y su continuación en los cuatro tomos del Auctarium donde se trata de temas tan diversos cuales son los salmos, regalismo, maternidad de la Virgen, Santa Teresa o Santa Rosa de Lima, el Empíreo, la misericordia y algunos otros tremas tratados en el Thesauris como la donación pontificia, la servidumbre, comercio, oficiales reales, minería, monopolio, lucro, impuestos así como la opiniones más y menos probables de escritores modernos y sus argumentos, la ignorancia invencible, bulas y breves, rituales, lo relativo al chocolate y la coca, diezmos y primicias, celebración de misas y obligación de las parroquias, las sedes vacantes, las misas en noches de navidad, gabelas, constituciones sinodales, jurisdicción de episcopados, indultos, dispensas, etc.

Tema destacable es su pensamiento teocrático, heredado de Solórzano y apoyado en autores reconocidos en la misma línea de pensamiento, como bien explica Castañeda Delgado (cap. XX). Para Avendaño, el Papa tiene domino absoluta y plenamente perfecto en lo temporal universal y los ejemplos son múltiples (Thesaurus, IV, 422) como sintetiza Castañeda en tres ejemplos nítidos: La Iglesia tiene dominio absoluta et undequaque perfectum; el Papa puede ceder el domino a principales infieles; sólo por la autoridad del romano pontífice se puede hacer la guerra a los infieles. Estas ideas, plenamente establecidas entre los canonistas, definidas por Bonifacio VIII en su Unam Santam, como dice Avendaño, colocan en manos del papa el poder espiritual y temporal o, como dice textualmente el segoviano en el índice de su Thesaurus: habere potestatem in temporalibus dogma certissimum ex pontifica definitione. Duo Gladis a Christo dati. El omnes oves commisisse.

Precisamente el tema teocrático, objeto de la tesis doctoral del prof. Castañeda, se percibe en la explicación de Avendaño y en las numerosas fuentes en las que se apoya; no obstante, conocedor de la controversia suscitada en torno a la propiedad privada de los infieles y la presunta jurisdicción del príncipe, trataba de hallar un punto de equilibrio entre estos y las ideas lascasianas acerca de la propiedad, como derecho natural. Las matizaciones de Avendaño ante posturas extremas y las objeciones expuestas han sido esquematizadas por Castañeda Delgado ${ }^{61}$ en los cuatro puntos que siguen: Para Acosta siguiendo las enseñanzas de Salamanca y Alcalá, que él tanto aprecia, y en oposición a Sepúlveda, Avendaño defiende la prevalencia de la sentencia que otorga a los infieles derecho de propiedad no significa la condenación de la contraria; en tanto que la condenación de la obra de Ginés de Sepúlveda por las universidades citadas puede ser contrapuesta por la aprobación romana (Thesaurus, IV, 421). La doctrina según la cual el dominio de

${ }^{61}$ Ibidem, 585. 
las cosas se perdía ipso iure por el pecado fue condenada por el concilio de Constanza; nuevamente Avendaño pone el mayor cuidado en acomodar posturas diciendo que los padres conciliares quisieron aminorar el dominio radical pero no el usufructo $^{62}$, a no ser por positiva intervención de la Iglesia pero; con el Concilio citado se condenaba a quienes defendieran que se pierde el dominio por cualquier pecado pero no a los que lo restringen a pecados especial, como la herejía o la infidelidad. Acerca de la doctrina expuesta en la bula Sublimis Deus, de Paulo III, que considera a los infieles con capacidad de títulos posesores de los que, como de su libertad, no pueden ser despojados, Diego de Avendaño matiza diciendo que el dominio absoluto y completo no se da en los infieles sino en la Iglesia, pero puede ésta cedérselo ut illi habeant, como lo tienen quienes han abrazado el cristianismo ya que si la infidelidad es la razón de la privanza del derecho, cesa tal razón al abrazar la fe. Del tal forma la Iglesia ya no puede trasladarlo a otro a no ser por una causa común a todos los fieles.

Finalmente, en la cuarta hace referencia a una R.C. de 1 de abril de 1580 por la que Felipe II ordena castigar a los descubridores que no cumplan la normativa porque "no por ser lo indios infieles pueden ser conquistados y sujetados por fuerza de armas"; a lo que Avendaño arguye que la real cédula no es argumento suficiente ya que es cierto que la infidelidad no da derecho a los fieles a invadir las tierras de los infieles, despojarlos de sus bienes y subyugarlos, a no ser con autorización papal pero, aún así, ha de ser regulado por la razón y la piedad cristiana y no pueden ser despojados de lo necesario para vida familiar ni siquiera con autorización del papa ni por cesión de los reyes ${ }^{63}$.

\section{A MODO DE CONCLUSIÓN}

Los protagonistas activos y pasivos han sido muchos en la etapa de fundación de los Reinos de las Indias; cada uno ha jugado su papel relevante en le Historia; numerosos nombres propios han alcanzado una notoriedad fuera de lo común y muy por encima de su entorno, más allá de la valoración que extemporánea y anacrónicamente quiera hacerse. Por lo que respecta a estos tres intelectuales segovianos y América, que tantos años, tan denodados esfuerzos y tantísimas páginas escribieron, su obra no solo es abrumadora, también interesante y merecedora de mayor atención de la que han recibido. La capacidad de trabajo que los tres exhibieron fue portentosa.

\footnotetext{
${ }^{62}$ Para Avendaño dominio radical y absoluto y perfecto son sinónimos; el útil y cedido son equivalentes. CASTAÑEDA, P (1996). La teocracia pontifical en las controversias sobre el Nuevo Mundo. México: UNAM, p. 586.

${ }^{63}$ AvenDaÑo, D. de. Op. cit., IV, p. 422.
} 
Figura 8. Portada del volumen primero de la obra cumbre de Avendaño

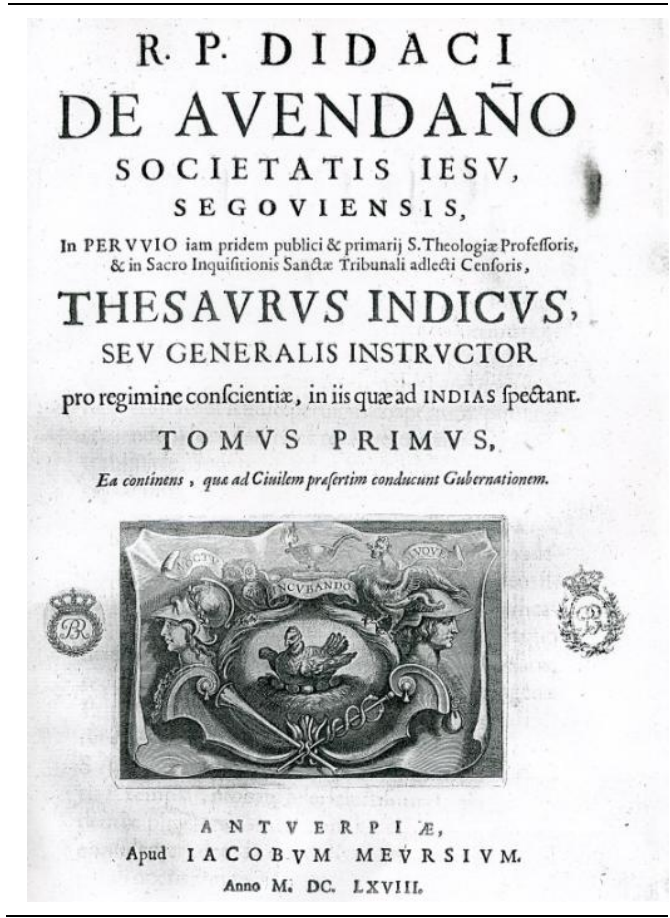

La materia americanista les interesó sobremanera porque era la temática más apasionante de la Europa de su tiempo y porque se vieron atraídos y hasta involucrados en las cuestiones que planteaba el Nuevo Mundo. Soto desde el campo ideológico, Avendaño en la realidad americana, Herrera en el conocimiento y comprensión de la participación española durante el primer medio siglo de su acción en Indias y la ordenación de su problemática.

No obstante, estas cuestiones eran tratadas con la diferenciación característica de la formación e intencionalidad de cada autor. El tema de las Bulas Alejandrinas, por ejemplo, la teocracia pontifical y el poder indirecto del papa muestran a un Avendaño (Thesaurus, I, 1) que defiende la donación papal porque la cuestión es si tal donación, pues si puede, cuando las entrega, no se equivoca, nec in iure nec in facto; si no puede, como él cree que sí, pues dona con autoridad y no se puede 
dudar de la autenticidad de tal donación. Creemos con Castañeda Delgado ${ }^{64}$ que Avendaño es un teócrata moderado, un tanto ecléctico, que desde Lima proyectaba, muy tardíamente, sobre América doctrinas de poderes pontificios que en otros tiempos habían sido sentencia común".

Figura 9. La marca de impresión de algunas obras de Domingo de Soto fue la inspiración para el emblema del Centro Universitario de Segovia que ha llevado su nombre.

(Como el resto de los grabados precedentes, procede de la Biblioteca de Fondo Antiguo de la Universidad Complutense).

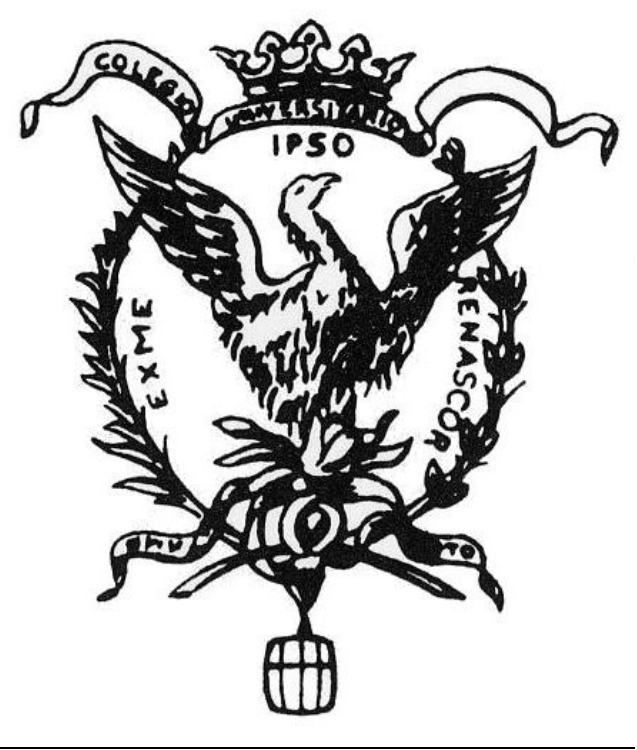

Domingo de Soto escribió, en latín y español, un tratado en defensa de los pobres, titulado "Deliberación en la causa de los pobres" (Salamanca, 1545); en él exponía cuánto interesaba conservar y aumentar la caridad a la vez que reflexionaba sobre la conveniencia de no consentir la existencia de vagabundos por ser origen de tantos daños. Resultó ser uno de los textos más razonados, humanitarios y profundos del derecho cuando se trata del pauperismo. Su

\footnotetext{
594.

${ }^{64}$ Véase su tesis doctoral así como la moderna edición corregida y aumentada de La teocracia,
} 
pensamiento dejó una huella profunda ${ }^{65}$. La referida obra fue recibida muy bien, como también lo habían sido la segunda edición corregida y aumentada de las Summulas (1539).

La Crónica oficial después de Herrera no mantuvo la línea del segoviano; los sucesivos cronistas oficiales no alcanzaron su nivel o se planearon otros objetivos (Juan Bautista Muñoz, por ejemplo) hasta enlazar con la Real Academia de la Historia $^{66}$. La Historia de los hechos de los castellanos fue singular por ser la primera en utiliza todas las fuentes disponibles. Es universalmente aceptado que tanta cantidad de libros y documentos utilizados hace que la calidad redactora de Herrera no se perciba demasiado en su gran libro, como ha sido enunciado. Herrera dedicó diecinueve años de su vida (1596-1615) a la redacción de las Décadas aunque compatibilizando esta tarea con otros cometidos. Ante el historiador aparecía un vasto espacio y un lapso cronológico importante por la cantidad de años (1492-1554) así como por la calidad de los "hechos" acaecidos en período tan particularmente intenso para el que se disponía de una abrumadora cantidad de documentación para cuyo uso dispuso Herrera de todo lujo de facilidades. Fue capaz de cumplir con la normativa vigente (Recopilación de las Leyes de los Reinos de las Indias, título 12, leyes I-III) sobre las obligaciones de su cargo: "Que el Cronista mayor escriba la Historia de las Indias... que vaya escribiendo la historia natural de ella...", sin decir falsedad, sin ocultar verdad

Así pues, es evidente que la obra de estos tres autores prolíficos, inédita o no vuelta a publicar desde que Soto, Herrera y Avendaño, respectivamente, la escribieron, exige un esfuerzo considerable, un trabajo abundante y un gasto cuantioso; es causa merecedora del esfuerzo investigador y de generosidad económica.

${ }^{65}$ Velarde Fuertes, J. Op cit., pp. 359-396.

${ }^{66}$ Cuestadomingo, M. La Crónica oficial de Indias [nota 6]. 